\title{
Study the Effect of Cardamom Extracts on Lactobacilli in Comparison to Chlorohexidine gluconate and De-ionized water (in vitro study)
}

\author{
Sara I. Khalil* \\ Wesal A. Al-Obaidi * \\ Wifaq M. Ali**
}

\author{
BDS \\ BDS, MSc \\ MBchB, FICMS
}

\begin{abstract}
:
Background: Various herbal extracts are known to provide therapeutic benefits in the oral cavity when used topically. One of these herbs is cardamom which is a dried fruit of the tall permanent herbaceous plant, have its place in the family Zingiberaceae.

Objectives: Test the effect of green and black cardamom extracts on Lactobacilli in comparison to chlorhexidine gluconate $0.2 \%$ and de-ionized water.

Materials and methods: Dried fruits of green and black cardamom were extracted by using alcohol $70 \%$ ethanol. Saliva was collected from seven volunteers. Agar well technique with different concentrations of green and black cardamom extracts was used to test the sensitivities of Lactobacilli, as well the effects of both cardamom extracts on viable counts of Lactobacilli.

Results: Lactobacilli were sensitive to different concentrations of green and black cardamom extracts starting with (5\%) to (40\%) using agar well diffusion technique. Both types of cardamom extracts green and black were effective in inhibition of Lactobacilli but still weaker than chlorhexidine gluconate $0.2 \%$. Highly significant reduction in the counts of bacteria were reported with cardamom extracts and chlorhexidine in comparison to neutral control after two hrs..

Conclusions: Both types of cardamom (green and black) showed an effect on Lactobacilli but still less than chlorhexidine.

Key words: Lactobacilli, black cardamom, green cardamom, chlorhexidine, de-ionized water.
\end{abstract}

\section{Introduction:}

The oral cavity is vital and consider as an integral part of human anatomy and its health is mostly related to the health of the rest of the body $(1,2)$. Dental caries and periodontal disease are the most common oral disease affect oral cavity (3). Dental caries is highly effected by the presence of acidogenic bacteria which increase the formation of dental caries like Streptococcus mutans (4). Although Mutans Streptococcus group are the main cause of tooth decay, other variations of bacteria can progress dental caries most commonly Lactobacilli (5), which contributes to the progression of dental caries $(6,7)$. From their name, Lactobacilli produce lactic acid and energy, the fermentation of sugars to lactate by homo-fermentative metabolism and their tolerant to low $\mathrm{pH}$ values are the two most important caries associated traits (8). Lactobacilli are rod-shaped, fermentative and facultative anaerobic or microaerophilic organotrop, Gram-positive bacteria of the genus Lactobacillus and family Lactobacillaceae $(9,10)$. Lactobacilli is usually benign, except in the oral cavity where they have been associated with tooth

* College of Dentistry, University of Baghdad.

** Dept. of Microbiology, College of Medicine, University of Baghdad. Email:mbm.ahsan@gmail.com decay. Lactic acid producing bacteria such as L. acidophilus, are widely used in the food industry for the production of yoghurt, cheese $(11,12)$, as well as it is important in the progression of caries which have been initiated by other acid producing bacteria such as S.mutans $(13,14)$. The optimal intervention for oral disease is not universally affordable because of high costs and limited resources, the use of chemical agents and food additives such as antibiotics causes many side effect like change the oxidation reduction potential of saliva (15-17). Antimicrobial activity of herbs and spices have been investigated as an alternative to antibiotic inorder to tackle these dangers. Herbal medicines are increasingly used as dietary supplements for treatment against different human disorders with their safety and efficacy $(18,19)$. Cardamom has its special field of application, it's a spice farmed in only a few places in the world including Sri Lanka, China, Laos, Nepal, Vietnam, India and Guatemala (20). The seeds of cardamom plant contain a variety of important minerals such as calcium, sulfur and phosphorus, they also contain volatile oil which formed about $5 \%$ of the seed's mass known with its medicinal properties and thus makes cardamom so valuable (21). There 
are two types of cardamom: green (small) and black (large), both have antimicrobial agents performing dental caries and periodontal disease accompanying oral bacteria on Gram positive and Gram negative bacteria (22-26).

\section{Materials and Methods:}

Stimulated salivary samples were collected from seven healthy persons from Baghdad -University, College of Medicine by chewing a piece of Arabic gum, after disappearance of salivary foam, $0.1 \mathrm{ml}$ of saliva is transferred to $0.9 \mathrm{ml}$ of sterile phosphate buffer saline (PBS) of $\mathrm{pH}$ 7.0-7.2 for microbiological analysis. Ten-fold dilution were performed, the inoculum was withdrawn from (10-3), $0.1 \mathrm{ml}$ was taken and spread in duplicate on the rogosa selective lactobacilli (RSL) agar which is the selective media for Lactobacilli. The plates were incubated aerobically for $48 \mathrm{hrs}$. at $37^{\circ} \mathrm{C}$. the colonies were determined according to morphological characteristic and Gram stain (27).Agar well technique was applied to study the antibacterial effects of different concentrations of alcoholic green and black cardamom extracts $(5 \%, 10 \%, 15 \%, 20 \%$, $25 \%, 30 \%, 35 \%, 40 \%$ ), compared with chlorhexidine $0.2 \%$ as a control positive and de-ionized water as control negative on MHA media. These experiments were conducted on seven isolates of Lactobacilli. MHA used in this experiment which were prepared and sterilized previously in sterile petri dish plates. To several plates Lactobacilli inoculum was spread, left at room temperature for 20 minutes. Several wells of equal size and depth were prepared in each agar plate; each well was filled with $0.1 \mathrm{ml}$ of the test agent. Plates were left at room temperature for one hour then incubated aerobically for $24 \mathrm{hrs}$. at $37 \mathrm{oC}$. Zone of inhibitions which is clear zone of no growth of the bacteria were measured across the diameter of each well by using a ruler.The viability counts of Lactobacilli from broth media, to which different concentrations of alcoholic extracts of green and black cardamom, chlorhexidine glugonate $0.2 \%$ and de-ionized water were added have been estimated in comparison to the control (broth and bacteria only). The procedure was carried on four isolates of Lactobacilli, the concentrations were $10 \%, 15 \%, 20 \%, 25 \%, 30 \%, 35 \%, 40 \%$ of alcoholic cardamom extracts for both types. Using brain heart infusion broth (BHI) which distributed in test tubes by $8.9 \mathrm{ml}$ to each tube, $0.1 \mathrm{ml}$ of the test agents was added to each tube except the control which was broth and bacteria only (28). From the control tube $0.1 \mathrm{ml}$ was transferred to $0.9 \mathrm{ml}$ of sterile normal saline. From dilution $10^{-5}, 0.1 \mathrm{ml}$ was taken and spread on RSL agar plates, incubated aerobically at $37^{\circ} \mathrm{C}$ for $48 \mathrm{hrs}$. the colony-forming unit per milliliter $(\mathrm{CFU} / \mathrm{ml})$ was counted. This value was considered as the initial count of bacteria. Study and control broth cultures were incubated aerobically for two hours at $37^{\circ} \mathrm{C}$. From each broth $0.1 \mathrm{ml}$ was transferred to $0.9 \mathrm{ml}$ of sterile PBS (pH 7.0). From dilution and $10^{-5}, 0.1 \mathrm{ml}$ was taken and spread on RSL agar plates and were incubated aerobically for $48 \mathrm{hrs}$. at $37^{\circ} \mathrm{C}$. The colony-forming unit per milliliter $(\mathrm{CFU} / \mathrm{ml})$ was counted.

\section{Results:}

Green and black cardamom extracts were prepared by a method for alcoholic extract, with a dark greenish-brown color for green cardamom and dark brownish black for black cardamom, both were oily and viscous consistency (Figure-1 A and B). Lactobacilli colonies appeared as spindle, star like shaped, circular, ovoid or heart like in appearance, white (or slightly yellow) in color on the selective Rogosa agar plates (Figure-2). Lactobacilli were gram's positive, non- spore forming rods catalase negative. In addition, Lactobacilli were non-motile when examined their under microscope by direct smear (Figure-3). In the sensitivities of Lactobacilli to different concentrations of both types of cardamom, chlorhexidine and deionized water in vitro, the diameter of inhibition zone was found to be increased as the concentrations of both types of cardamom extracts increased. De-ionized water showed no zone of inhibition while chlorhexidine showed the highest zones of inhibition compared to both cardamom extracts, as one way ANOVA was performed among different concentrations, chlorhexidine and D.W. (Table-1). Also a statistical analysis was done between each same concentrations of both extracts, nonsignificant difference was found between both types (Table-2). The counts of Lactobacilli were tested with alcoholic extracts of green and black cardamom, chlorhexidine, de-ionized water and control (broth+LB) (Table-3). Paired t- test was used to compare between initial count of bacteria and count of bacteria after two hrs. Statistically, highly significant increase in number of bacteria was recorded after two hrs. (Table-4). Finally, LSD between agents in comparison with initial counts and counts after two hrs.was done (Table-5).

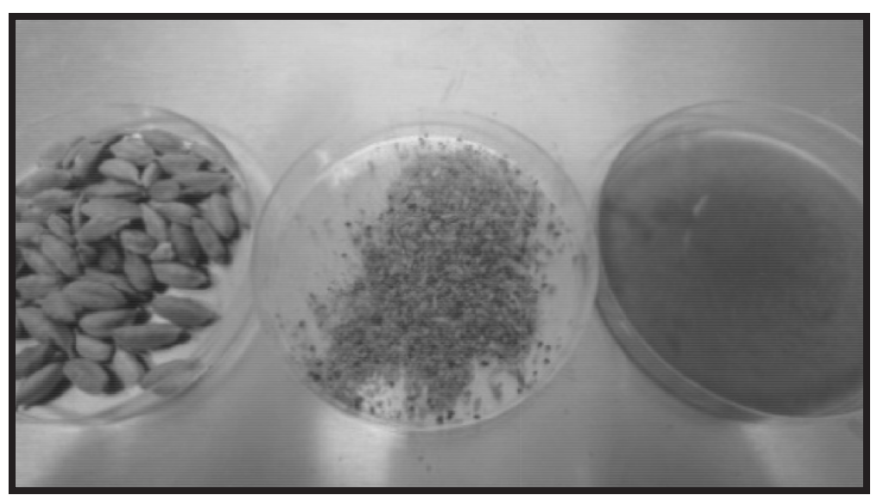




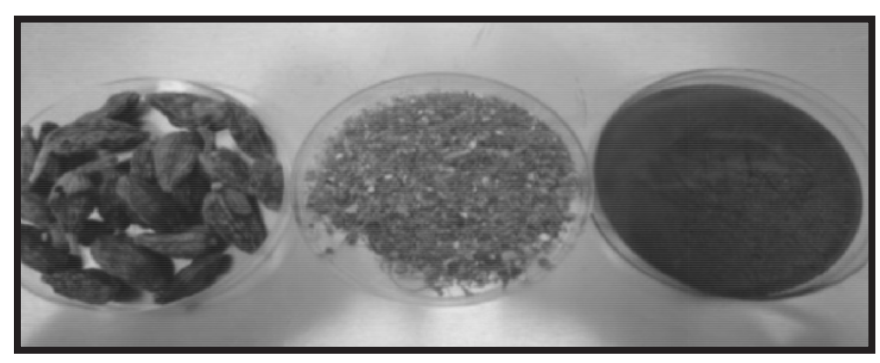

Figure (1): A. Small cardamom extract product. B. Large cardamom extract product.

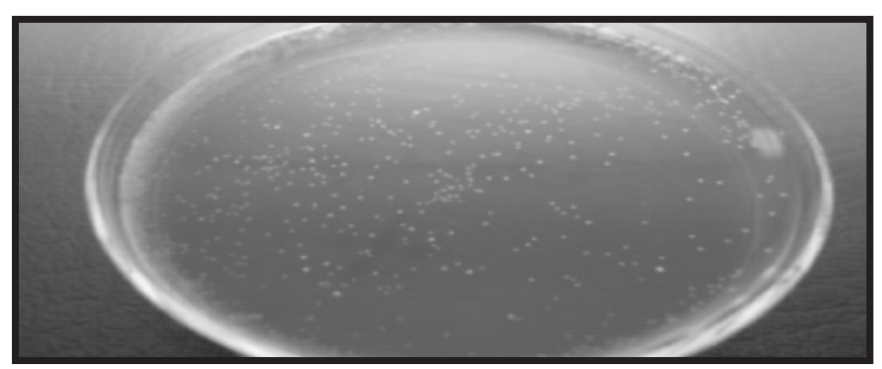

Figure (2): Lactobacilli colonies on Rogosa Agar.

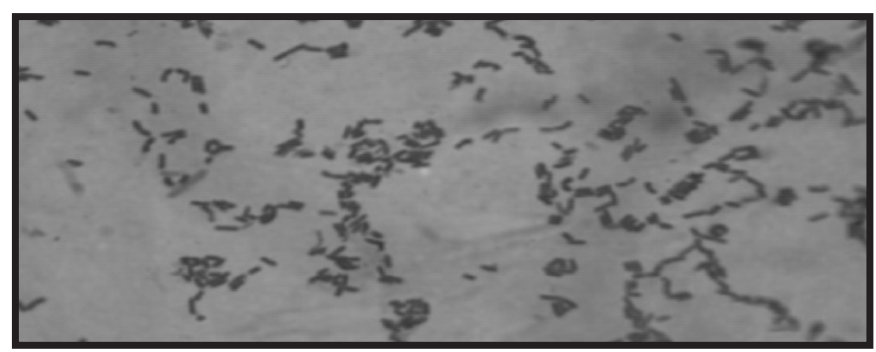

Figure (3): Gram's stain of Lactobacilli cells from pure culture (1000 $\times$ magnification)

Table(1): Lactobacilli inhibition zone to different concentrations by different agents (Agar well diffusion methods).

\begin{tabular}{|c|c|c|c|c|c|}
\hline Agents & Conc. & No. & *Mean & \pm SD & ANOVA test \\
\hline CHX & $0.2 \%$ & 7 & 19.00 & 1.00 & \multirow{10}{*}{$\begin{array}{c}F=78.13 \\
P=0.00 \\
d f=9 \\
H S\end{array}$} \\
\hline \multirow{8}{*}{$\begin{array}{c}\text { Small } \\
\text { cardamom }\end{array}$} & $5 \%$ & 7 & 2.28 & 1.88 & \\
\hline & $10 \%$ & 7 & 3.85 & 0.78 & \\
\hline & $15 \%$ & 7 & 4.85 & 1.57 & \\
\hline & $20 \%$ & 7 & 6.65 & 1.92 & \\
\hline & $25 \%$ & 7 & 7.05 & 1.86 & \\
\hline & $30 \%$ & 7 & 7.62 & 1.92 & \\
\hline & $35 \%$ & 7 & 8.57 & 1.39 & \\
\hline & $40 \%$ & 7 & 9.20 & 1.13 & \\
\hline D.W. & & 7 & 0.00 & 0.00 & \\
\hline CHX & $0.2 \%$ & 7 & 19.00 & 1.00 & \multirow{10}{*}{$\begin{array}{c}F=154.09 \\
P=0.00 \\
d f=9 \\
\text { HS }\end{array}$} \\
\hline \multirow{8}{*}{$\begin{array}{c}\text { Large } \\
\text { cardamom }\end{array}$} & $5 \%$ & 7 & 2.00 & 1.91 & \\
\hline & $10 \%$ & 7 & 3.37 & 0.83 & \\
\hline & $15 \%$ & 7 & 5.94 & 0.47 & \\
\hline & $20 \%$ & 7 & 7.08 & 0.92 & \\
\hline & $25 \%$ & 7 & 7.82 & 1.28 & \\
\hline & $30 \%$ & 7 & 8.62 & 1.49 & \\
\hline & $35 \%$ & 7 & 9.37 & 1.11 & \\
\hline & $40 \%$ & 7 & 10.08 & 1.02 & \\
\hline D.W. & & 7 & 0.00 & 0.00 & \\
\hline
\end{tabular}

* (mm)
Table (2): Effect of the same concentrations of green and black cardamom extracts on Lactobacilli inhibition zone.

\begin{tabular}{ccccccccc}
\hline \multicolumn{1}{c}{$\begin{array}{c}\text { Small } \\
\text { Cardamom }\end{array}$} & \multicolumn{2}{c}{$\begin{array}{c}\text { large } \\
\text { cardamom }\end{array}$} & t-test & df & P-value & Description \\
\cline { 2 - 8 } & Mean* & SD \pm & Mean* & SD \pm & & & \\
\hline $5 \%$ & 2.28 & 1.88 & 2.00 & 1.91 & -0.28 & 12 & 0.78 & NS \\
\hline $10 \%$ & 3.85 & 1.57 & 3.37 & 0.83 & -0.72 & 12 & 0.48 & NS \\
\hline $15 \%$ & 4.85 & 1.57 & 5.94 & 0.47 & 1.74 & 12 & 0.10 & NS \\
\hline $20 \%$ & 6.65 & 1.92 & 7.08 & 0.92 & 0.53 & 12 & 0.60 & NS \\
\hline $25 \%$ & 7.07 & 1.86 & 7.82 & 1.28 & 1.90 & 12 & 0.38 & NS \\
\hline $30 \%$ & 7.62 & 1.92 & 8.62 & 1.49 & 1.08 & 12 & 0.29 & NS \\
\hline $35 \%$ & 8.57 & 1.39 & 9.37 & 1.11 & 1.18 & 12 & 0.25 & NS \\
\hline $40 \%$ & 9.20 & 1.13 & 10.08 & 1.02 & 1.53 & 12 & 0.15 & NS \\
\hline$*(\mathrm{~mm})$ & & & & & & & &
\end{tabular}

Table (3): Effect of different concentrations of green and black cardamom extracts, chlorhexidine and de-ionized water on viable count of Lactobacilli $\mathrm{X10}^{-5}$ in vitro.

\begin{tabular}{|c|c|c|c|c|c|}
\hline Agents & Conc. & No. & *Mean & $\pm \mathrm{SD}$ & ANOVA \\
\hline CHX & $0.2 \%$ & 4 & 6.00 & 3.46 & \multirow{9}{*}{$\begin{array}{c}F=36.35 \\
P=0.00 \\
\text { df }=8 \\
\text { HS }\end{array}$} \\
\hline \multirow{7}{*}{$\begin{array}{c}\text { Small } \\
\text { cardamom }\end{array}$} & $10 \%$ & 4 & 193.75 & 42.69 & \\
\hline & $15 \%$ & 4 & 164.25 & 51.37 & \\
\hline & $20 \%$ & 4 & 145.00 & 44.53 & \\
\hline & $25 \%$ & 4 & 99.50 & 35.18 & \\
\hline & $30 \%$ & 4 & 72.50 & 18.64 & \\
\hline & $35 \%$ & 4 & 51.50 & 1.00 & \\
\hline & $40 \%$ & 4 & 40.00 & 9.12 & \\
\hline D.W. & & 4 & 296.25 & 4.787 & \\
\hline СHX & $0.2 \%$ & 4 & 6.00 & 3.46 & \multirow{9}{*}{$\begin{array}{c}F=19.75 \\
P=0.00 \\
d f=8 \\
\text { HS }\end{array}$} \\
\hline \multirow{7}{*}{$\begin{array}{c}\text { Large } \\
\text { cardamom }\end{array}$} & $10 \%$ & 4 & 187.00 & 37.74 & \\
\hline & $15 \%$ & 4 & 162.50 & 43.30 & \\
\hline & $20 \%$ & 4 & 140.00 & 57.59 & \\
\hline & $25 \%$ & 4 & 121.25 & 66.63 & \\
\hline & $30 \%$ & 4 & 88.75 & 44.22 & \\
\hline & $35 \%$ & 4 & 62.50 & 26.29 & \\
\hline & $40 \%$ & 4 & 43.75 & 17.01 & \\
\hline D.W. & & 4 & 296.25 & 4.78 & \\
\hline
\end{tabular}


Table (4): :Initial count of Lactobacilli and count of it after two hrs. $\left(\mathrm{X10}^{-5}\right)$.

\begin{tabular}{cccc}
\hline & *Mean & \pm SD & Paired t-test \\
\hline Initial count & 96.25 & 4.78 & $\begin{array}{c}t=-14.93 \\
P=0.00 \\
\text { df }=3 \\
\text { HS }\end{array}$ \\
\hline Count after 2 hrs. & 223.75 & 20.56 & \\
\hline
\end{tabular}

*(CFU/ml)

Table (5): LSD between agents in comparison with initial counts and counts after two hrs..

\begin{tabular}{|c|c|c|c|c|c|c|c|}
\hline \multirow{2}{*}{\multicolumn{2}{|c|}{ Conc. }} & \multicolumn{3}{|c|}{ Initial count } & \multicolumn{3}{|c|}{ Count after two hrs. } \\
\hline & & $\begin{array}{c}\text { *Mean } \\
\text { Difference }\end{array}$ & P-value & Description & $\begin{array}{c}\text { *Mean } \\
\text { Difference }\end{array}$ & P-value & Description \\
\hline \multirow{9}{*}{ 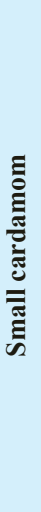 } & $10 \%$ & 97.50 & 0.00 & HS & -30.00 & 0.13 & NS \\
\hline & $15 \%$ & 68.00 & 0.00 & HS & -59.50 & 0.01 & $\mathbf{S}$ \\
\hline & $20 \%$ & 48.75 & 0.01 & $\mathbf{S}$ & -78.75 & 0.00 & HS \\
\hline & $25 \%$ & 3.25 & 0.87 & NS & -124.25 & 0.00 & HS \\
\hline & $30 \%$ & -23.25 & 0.23 & NS & -151.25 & 0.00 & HS \\
\hline & $35 \%$ & -44.75 & 0.03 & $\mathbf{S}$ & -172.25 & 0.00 & HS \\
\hline & $40 \%$ & -56.25 & 0.01 & $\mathbf{S}$ & -183.75 & 0.00 & HS \\
\hline & CHX & -90.25 & 0.00 & HS & -217.75 & 0.00 & HS \\
\hline & D.W. & 200.00 & 0.00 & HS & 72.50 & 0.00 & HS \\
\hline \multirow{9}{*}{ 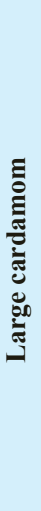 } & $10 \%$ & 91.25 & 0.00 & HS & -36.25 & 0.16 & NS \\
\hline & $15 \%$ & 66.25 & 0.01 & $\mathbf{S}$ & -61.25 & 0.02 & $\mathbf{S}$ \\
\hline & $20 \%$ & 43.75 & 0.09 & NS & -83.75 & 0.00 & HS \\
\hline & $25 \%$ & 25.00 & 0.33 & NS & -102.50 & 0.00 & HS \\
\hline & $30 \%$ & -7.50 & 0.77 & NS & -135.00 & 0.00 & HS \\
\hline & $35 \%$ & -33.75 & 0.19 & NS & -161.25 & 0.00 & HS \\
\hline & $40 \%$ & -57.50 & 0.03 & $\mathbf{S}$ & -185.00 & 0.00 & HS \\
\hline & CHX & -90.25 & 0.00 & HS & -217.75 & 0.00 & HS \\
\hline & D.W. & 200.00 & 0.00 & HS & 72.50 & 0.00 & HS \\
\hline
\end{tabular}

\section{Discussion:}

Green and black cardamom with alcoholic extract of different concentrations shown an effect on Lactobacilli by tested on two experiments (sensitivity and viable count), the effect increased as the concentration increased since the diameters of zones of inhibition were increased as the concentration of both cardamom types extract increased from 5\% to $40 \%$ but still lower than chlorhexidine $0.2 \%$. This is true as it was found a highly significant reduction in the viable counts of Lactobacilli with increased concentrations from $10 \%$ to $40 \%$.
This indicates that both cardamom extract has an effect on the growth of this type of bacteria mainly involved in the process of dental caries. All concentrations of cardamom extract were shown lower inhibition zone than chlorhexidine. The de-ionized water had zero effect on the bacteria appearing by absence of inhibition zone and there was non- significant difference in the counts of bacteria, this could be explained by complete resistance of these bacteria for de-ionized water. Chlorhexidine is more effective in reduction the count of bacteria compared to cardamom extract. The present study agrees with previous study concerning green cardamom effect on L. acidophilus, which showed an effect on bacterial inhibition zone, while disagrees with the same study with black cardamom which showed no effect on L. acidophilus (29). Both cardamom extracts were achieved the aims of inhibiting the growth of bacteria by using their essential oil extract, as the essential oil and oleoresin occupy large amount of their structure which impart the quality $(30,31)$. The mechanism of antimicrobial action appear to be on cell membrane by disrupting its structure causing cell leakage and cell death, also by blocking the membrane synthesis and cause inhibition of cellular respiration (32). Besides, they penetrate into the cell membrane and exert their biological action because of high volatility and lipophilicity of the essential oils (33). Also the results showed non -significant differences between both types of cardamom extracts on sensitivity and viable count of bacteria. The results of black cardamom in the present study and its low price compared with small cardamom and more popularity in many countries in the world; give a great hope to import and use black cardamom in our life as food additive as well as in many medical and dental applications, not as a substitution for green cardamom but as a unique spice used in many spicy dish. Also there extractions were used as an ingredient in many antibacterial material like mouth wash and dentifrices.

\section{Author contribution:}

Sara I. Khalil: Master student perform the study protocol including acquisition of data collection and doing concerned tests.

Wesal A. Al-Obaidi: Supervision, study design, study conception, statistical analysis, support in writing thesis. Wifaq M. Ali: Supervision, support in writing thesis, support in laboratory work for doing concerned tests.

\section{References:}

1. Battle C. Essentials of public health biology: A guide for the study of pathophysiology. Jones and Bartlett publishers, 2009. 
2. Harnandez J, Aguilar Diaz F, Vilchis M. Oral health related quality of life. UNAM, Leon, Gto, Mexico, 2015.

3. Snyder G, Haveman J. Burden of oral disease in Machigan. Machigan department of community health, 2013.

4. Prabu G, Gnanamani A, Sadulla S. Guaiijaverin- a plant flavonoid as potential antiplaque agent against Streptpcoccus mutans. J Appl Microbiol 2006; 101: 487- 495.

5. Leroy F, Verluyten J, De vuyst L. Effect of different spices used in production of fermented sausages on growth of curvacin: A production by Lactobacillus curvatus. AEM J 2004; 70(8):4807-4813.

6. Summitt $J$, Robbins $J$, Schwartz $R$, dos Santos $J$. Fundamentals of operative dentistry, a contemporary approach. Quintessence publishing, 2006.

7. Fejerskov O, Kidd E. Dental caries, the disease and its clinical management. 2nd ed. Blackwell Munkgard Ltd, 2008.

8. Brenner M, Krieg N, StaleyJ. Berge's Manual of systematic bacteriology. 10th ed. Williams and Wilkins Co, USA, 2005.

9. Macarova K, Slesarev A, Wolf Y, Sorokin A, Mirkin B, Koonin E. Comparative genomics of the lactic acid bacteria. Proc Natl Acad Sci USA 2006; 103: 15611-15616.

10. Forest $P$, Santivarangkna $C$. Advances in probiotic technology: Identification and enumeration of probiotics. CRC Press, 2015: 105.

11. Giraffa G, Chanishvili N, Widyastuti Y. Importance of lactobacilli in food and feed biotechnology. Research Micribiol J 2010; 161: 480-487.

12. Murtaza M, Huma N, Sameen A, Saeed M, Murtaza M. Minerals and lactic acid contents in buffalo milk cheddar cheese; a comparison with cow. J Food and Nutrition Res 2014; 2(8): 465-468.

13. Kleinberg L. A mixed-bacteria ecological approach to understanding the role of the oral bacteria in dental caries causation: an alternative to Streptococcus mutans and the specific-plaque hypothesis. Crit Rev Oral Biol Med 2002; 13(2): 108-125.

14. Karpenski T, Szkaradkiewicz A. Microbiology of dental caries. J Bio and Earth Sci 2013; 3(1): M21-M24.

15. Rangan C, Barceloux D. Food additives and sensitivities. Dis Mon J 2009; 55: 292-311.

16. Wroblewska B. Influence offood additives and contaminants (nickel and chromium) on hypersensitivity and other adverse health reactions: A review. Pol J Food Nutr Sci 2009; 59: $287-$ 294.

17. Lindgren J, Uvdal P, Sjovall P, Nilsson D, Engdahl A, Schultz B, Thiel V. Skin of the cretaceous mosasaur plotosaurus: implications for aquatic adaptations in giant marine reptiles. Biology letters J 2009; 5:528-531.

18. Rajani M, Kanaki N. Phytochemical standardization of herbal drugs and polyherbal formulations: Bioactive molecules and medicinal plants. Springer: Berlin Heidelberg, 2008: 349-69.

19. Rai M, Chinkindas M. Natural antimicrobial in food safety and quality. CABI Publishing, 2010.

20. Martinot E. Renewables 2005 global status report. Diane Publishing, Washington, 2010.

21. Tisserand R, Young R. Essential oil safety: A guide for health care professionals. Elsevier Health Sciences, 2013.

22. Agaoglu S, Dostbil N, Alemdar S. Antimicrobial effect of seed extract of cardamom (Elettaria cardamomum- Maton). JYYU Vet Fak Derg 2005; 16(2): 99-101.

23. El Malti J, Mountassif D, Amarouch H. Antimicrobial activity of Elettaria cardamomum: toxicity, biochemical and histological studies. Food Chem J 2007; 104: 1560-1568.

24. Norajit K, Laohakunjit N, Kerdchoechuen O. Antibacterial effect of five zingiberaceae essential oils. Molecules J 2007; 12(9): 2179-2180.

25. Rayes A. Study the effect of coffee and cardamom on the viability of some probiotic strains and their cytotoxicity. Academic J 2012; 10(12): 11.

26. Akrayi H. Antibacterial effect of seed extracts of cardamom (Elettaria cardamomum) against Staphylococcus aureus and Proteus mirabilis. Tikrit J pure science 2012; 17(2): 14-18.

27. Koneman E, Schreckenberge P, Allens $S$, Jr W, Janada W. Diagnostic microbiology. 4th ed. J.B. Lippincott Co.. USA, 1992.

28. Baron E, Peteson L, Fingold S. Methods for testing antimicrobial effectiveness. In: Bailey and scott's diagnostic microbiology, 9th ed. USA-Missouri, CV Mosby Co, St. Louis, 1994.

29. Aneja K, Joshi R. Antimicrobial Activity of Amomum subulatum and Elettaria cardamomum against dental caries causing microorganisms. J Ethnobotanical 2009; 13: 840-9.

30. Weiss L. Spice crops. 1st ed. CAB, London, 2002.

31. Kappor I, Singh B, Singh G, Isidorov V, Szczepaniak L. Chemistry, antifungal and antioxidant activities of cardamom (Amomum subulatum) essential oil and oleoresins. Int J Essent Oil Therap 2008; 2 (1): 29-40.

32. Harris R. Progress with superficial mycosis using essential oils. Int J Aromatherapy 2002; 12: 83-91.

33. Inouye $S$, Abe S, Yamaguchi H, Asakura M. Comparative study of antimicrobial and cytotoxic effects of selected essential oils by gaseous and solution contacts. Int J Aromatherapy 2003; 13 (1): 33-41. 